\title{
Burr Tipi III Dağılımının İlerleyen Tür Tip II Sağdan Sansürlü Örnekleme Dayalı Parametrelerinin EM Tahmin Edicisi
}

\author{
Özlem GÜRÜNLÜ ALMA@*1, Sinem ARAY²
}

\author{
${ }^{1}$ Muğla Sıtkı Koçman Ünv., Fen Fakültesi, İstatistik Bölümü, Muğla, Türkiye \\ ${ }^{2}$ Muğla Sitkı Koçman Ünv., Fen Bilimleri Enstitüsü, İstatistik ABD, Muğla, Türkiye
}

Geliş / Received: 27/09/2019, Kabul / Accepted: 01/06/2020

\section{$\ddot{O} \mathbf{z}$}

Bu çalışmada, Burr Tipi III Dağılım'a ait bilinmeyen parametrelerinin istatistiksel tahmini, ilerleyen tür tip II sağdan sansürlü örneklem durumunda incelenmiştir. Bilinmeyen parametrelerin en çok olabilirlik tahmin edicileri Newton-Raphson yöntemi ve Beklenti Maksimizasyonu (EM) algoritması kullanılarak elde edilmiş, parametrelerin asimptotik güven aralıkları kayıp değer prensibine dayalı Fisher bilgi matrisi aracıllğılyla bulunmuştur. Tahmin edicilerin performansları farklı sansür şemaları ve parametre değerleri için benzetim çalıșması yoluyla karşılaştırılmıștır. Ayrıca çalıșmanın daha açıklayıcı olması amacıyla gerçek bir yaşam verisi örneği verilmiştir.

Anahtar Kelimeler: İlerleyen Tür Tip II Sağdan Sansürlü Örnekleme, En Çok Olabilirlik Tahmin Edicileri (MLE), Olabilirlik Fonksiyonu, Burr Tipi III Dağılım, Sansürlü Veri, Beklenti Maksimizasyonu (EM) Algoritmas1, Newton-Raphson yöntemi.

\section{Parameter Estimation of Burr Type III Distribution Under Progressive Type II Censored Sample Using EM Algorithm}

\begin{abstract}
Abctract
In this study, the statistical estimation of the unknown parameters of the Burr Type III Distribution is examined in the case of the progressive type II right censored sample. The maximum likelihood estimators of the unknown parameters were obtained using the Newton Raphson and the Expectation Maximization (EM) algorithm and the asymptotic confidence intervals of the parameters were found through the Fisher information matrix based on the missing value principle. The performances of the estimators are compared by means of a simulation study for different censoring schemes and parameter values. Also, a real-life example is given in order to make the study more descriptive.
\end{abstract}

Keywords: Progressively Type II Censored Samples, Maximum Likelihood Estimator, Likelihood Function, Burr Type III Distribution, Censored Data, Expectation Maximization (EM) Algorithm

\section{Giriş}

Yaşam analizi, ilgilenilen herhangi bir olayın ortaya çıkmasına kadar geçen süreyi modelleyen, sağlık alanında daha çok başvurulan, mühendislik alanında güvenilirlik veya güvenilirlik analizi, iktisat ve sosyoloji alanlarında ise süre analizi veya süre modellemesi olarak adlandirılan istatistiksel bir analiz yöntemidir. Burada olay: bozulma, ölüm ve başarısızlık olarak ifade edilebilir. $\mathrm{Bu}$ durumları inceleyebilmek, zaman kayb1 ve maliyet gibi nedenlerden dolayı her zaman mümkün olmayabilir. Örneğin; hane halk1 araştırmasında aile, gelirlerinin tamamını beyan etmekten kaçınabilir (Yazıc1, 2005). Verinin tamamına erişemediğimiz bu gibi durumlarda araştırmacı ya kayıp verileri göz ardı edecek ya da farklı teknikler 
uygulayarak bu sansürlü verileri tamamlama yoluna gitmeyi tercih edecektir (Yazıc1, 2005).

Yaşam ve güvenirlilik analizlerinde yaşam süresi tam olarak bilinmeyen olaylar sansürlü gözlem olarak adlandırılır. Literatürde çeşitli sansürleme türleri mevcuttur, bunlar; sağdan sansürleme, soldan sansürleme, ikili sansürleme ve aralık sansürlemesidir. Sağdan sansürleme, başarısızlık olarak adlandırılan olay, çalışma için belirlenen bir durma zamanına kadar gerçekleşmezse, bireyin yaşam süresinin uzunluğu çalışmanın durma zamanının sağ tarafına geçer. Böyle bir durumda bireyin yaşam süresi kesin olarak bilinmeyecek ve gözlemlenemeyecektir. Soldan sansürlemede, gözlenmek istenen olay bazı bireyler için, verilen zamana gelmeden önce gerçekleşmiştir. Bazı çalışmalarda soldan sansürlemenin meydana geldiği durumlarda, sağdan sansürleme de aynı zamanda ortaya çıkabilir, bu gibi durumlar ikili sansürlemedir. Aralık sansürlemesi ise, çalışmaya konu olan olayın meydana gelme süresi, bir aralıkta ifade edilir. Beklenilen olay iki zaman noktası arasında gerçekleşmiştir ve gerçekleşme anı hakkında bilgi yoktur bu da aralık sansürlemesi olarak adlandırılmaktadır.

Sağdan sansürleme, kendi içinde bazı alt gruplara ayrılmaktadır, bunlar; Tip I sansürleme, Tip II sansürleme, İlerleyen tür tip II sansürleme ve Bağımsız rasgele sansürleme' dir (Kale, 2003). Tip I sansürleme olarak adlandırılan sansürleme modeli, $\mathrm{t}$ gibi önceden belirlenmiş bir zamandan önce, sistemdeki bozulan birimlerin bozulma zamanının gözlenmesi durumudur. Tip II sansürleme olarak adlandırılan sansürleme modeli, n birimden oluşan bir sistemin bozulan $m \leq n$ biriminin bozulma zamanının gözlenmesi durumudur (Kale, 2003).

İkinci tip sansürlemenin en çok kullanılan türü, ilerleyen tür tip-II sağdan sansürlemedir. $\mathrm{Bu}$ sansürleme modelinde, $\mathrm{n}$ sayıda özdeş bileşen yaşam analizine tabi tutulur. Sistemde meydana gelen 1. bozulma ile rasgele $R_{1}$ sayıda bileşenin sistemden çekildiğini, daha sonra geriye kalan $n-R_{1}-1$ bileşenden, 2. Bozulma gerçekleşmesi ile rasgele $R_{2}$ sayıda bileşenin sistemden çekildiğini ve böylece $\mathrm{m}$. bozulmanın gerçekleşmesinden sonra rasgele $R_{m}$ sayıda bileşenin sistemden çekilmesiyle $\mathrm{m}$ bileşenin bozulma zamanı gözlenir. $\mathrm{Bu}$ şekilde elde edilen $\mathrm{m}$ hacimli örneklem, ilerleyen tür tip-II sağdan sansürlü örneklemdir. Burada $\quad \sum_{j=1}^{m}\left(R_{j}+m\right)=n$ 'dir. $\mathrm{Bu}$ durumda, $\left(R_{1}, R_{2}, R_{3}, \ldots, R_{m}\right) \quad$ ve sansürleme şeması $\left(X_{1}, X_{2}, X_{3}, \ldots, X_{m}\right)$ 'e ise gözlenen veriler denilir (Balakrishnan ve Aggarwala 2000).

Yaşam analizinde, elde edilen veriye hangi dağılımın uygulanacağı oldukça önemlidir. $\mathrm{Bu}$ nedenle, model seçimi yapılırken ilk olarak modelin veriye uygunluğu için gerekli testin yapılması gerekir. Model veriye uygunsa parametrik test varsayımlarının sağlanıp sağlanmadığına bakılarak modelin geçerliliği ile ilgili gerekli analizler yapılmaktadır. Yaşam analizlerinde, yaşam süreleri verilerini modelleyebilmek için kullanılan dağılımlardan Burr Dağılımı, on iki birikimli dağılım fonksiyonunu içeren bir dağılım ailesinden oluşmaktadır. Bu aileden, Burr tipi III dağılımı, Log-lojistik, Weibull ve Burr XII gibi dağılımlar içinden çarpıklık ve basıklık açısından daha geniş alana izin verir. $\mathrm{Bu}$ çalışmada, Burr Tipi III Dağılımının parametrelerinin tahmin edilmesinde kapalı bir form olmaması nedeniyle, parametrelerin tahmin edilmesinde; Newton Raphson yöntemi ve kayı gözleme dayalı Beklenti Maksimizasyonu (EM) Algoritması kullanılmıştır.

Günümüze kadar ilerleyen tür tip II sağdan sansürlü örnekleme dayalı ve EM algoritması ile ilgili birçok çalışma gerçekleştirilmiştir. $\mathrm{Bu}$ çalışmalardan bazıları aşağıdaki gibi özetlenebilir: 
Balakrishnan ve Sandu (1995), ilerleyen tür tip-II sansürlü örneklemi oluşturma yöntemini vermiştir

Balakrishnan ve Aggarwala (2000), çalışmalarında ilerleyen tür sansür teorisi ve uygulamalarını geniş bir şekilde anlatmışlardır.

Dempster, Laird ve Rubin (1977), EM algoritmasinin genel formülasyonunu sunmuşlardır.

Zhu, Lee, Wei ve Zhou (2001), mevcut yöntemlerin çözmekte zorlandığı problemlere uygulanabilecek bir yöntem sunmuşlar, EM algoritmasındaki tam olmayan en çok logolabilirlik fonksiyonunun koşullu beklenen yaklaşımını genelleştirmişlerdir.

Terzi (2003), doktora tezinde, sağdan sansürlü veriler için sağkalım analizi yöntemlerini kullanmış ve gerçek veriler üzerinde uygulamasını gerçekleştirmiştir. Sağkalım fonksiyonları arasındaki farkları parametrik olmayan testlerle bulmuş, iki sağkalım fonksiyonunu karşılaştıran testleri birbirleriyle karşılaştırmıştır. Sağkalım sürelerine etkileri araştırılan prognostik faktörler, yarı parametrik bir yöntem olan Cox regresyon yöntemi ile incelenmiştir.

Kale (2003), tarafindan hazırlanan tez çalışmasında ilerleyen tür tip-II sansürlenmiş sıra istatistikleri ve dağılım özellikleri konusu incelenmiștir.

Kuş (2004), tez çalışmasında, tam ve sansürlü verilere dayalı Burr XII, Gompertz ve Pareto I dağılımlarının parametrelerinin güven aralıkları ve güven bölgeleri, ilerleyen tür tip-II sağdan sansürlü örneklemlere dayalı olarak elde edilmiştir.

Kuş (2005), yapmış olduğu çalışmasında, düzgün dağılımın parametrelerinin ilerleyen tür tip-II sağdan sansürlü örnekleme dayalı Jacknife tahmin edicilerini elde etmiştir.

Yazıcı (2005), tez çalışmasında, kayıp veri içeren problemler için parametre tahmini hesaplamalarında, son yıllarda yoğun olarak kullanılan EM algoritması ve uzantılarının tanitilmasi amaçlanmıștır. EM algoritmasının sözel ve kuramsal olarak genel işleyişi ve özellikleri verilmiştir. Normal dağılıma sahip iki örneklem üzerinde, farklı kayıp veri problemleri tasarlanarak benzetim çalışması yapılmıştır.

Bairamov ve Eryılmaz (2006), Bu çalışmada çok değişkenli gözlemler için ilerleyen tür tip-II sansürlü sıra istatistikleri konusu ele alınmıştır.

Saraçoğlu, Kınacı ve Kuş (2006), Burr XII Dağılımının Parametresinin İlerleyen Tür Tip II Sağdan Sansürlü Örneklemlere Dayalı En Küçük Kareler Tahmini üzerinde çalışılmıştır.

İnceoğlu (2013), çalışmasında Turgut Özal Tıp Merkezi Karaciğer Nakil Enstitüsünde nakil yapılan hastalardan alınan veriler yardımıyla sağkalım analizi yöntemlerinin (Yaşam Tablosu Analizi, Kaplan-Meier Analizi, Cox Regresyon Analizi) sonuçlarını birbirleriyle karşılaştırmak amacı ile gerçekleştirmiştir.

Demir (2015), tezinde, ilerleyen tür tip II sansürleme altında, bazı yaşam zamanı dağılımlarının parametreleri için en çok olabilirlik ve lindley yaklaşımı kullanılarak yaklaşık bayes tahmin edicileri elde etmiş ve bu tahmin edicilerin yanları ve hata kareler ortalamaları Monte Carlo Benzetim metodu kullanılarak karşılaştırılmıştır.

Arabi Belaghi, Valizadeh Gamchi, Bevrani ve Gürünlü Alma (2016), İlerleyen Tür Sansür Kullanılarak EM ve SEM Algoritmalarına Dayalı Burr Type III Tahmini isimli makalelerinde, ilerleyen tür sansürleme kullanılarak iki parametreli Burr tip III dağılımının parametreleri kapalı formda elde edilemeyeceğinden EM ve SEM algoritma tahmincileri elde edilmiştir. Gerçek veri kullanılarak yapılan benzetim çalışmasıyla beyaz kan hücreleri kanserli hastaların analizi yapılarak SEM, EM, MLE sonuçları karşılaştırılmıştır. 
Aray (2018) yapmış olduğu tez çalışmasında, ilerleyen tür tip II sansürleme altında, Burr tipi III dağılımının parametreleri için Newton Raphson ve EM yaklaşımı kullanılarak tahmin edicileri elde etmiş ve bu tahmin edicilerin güven aralıkları ve hata kareler ortalamalarını Monte Carlo Benzetim metodu kullanılarak karşılaştırmıştır.

Çalışmanın ilerleyen bölümleri şu şekildedir: ikinci bölümde, Burr tipi III dağılımın ilerleyen tür Tip II sansürlü örneklem için parametre tahminleri anlatılmıştır. Üçüncü bölümde, benzetim çalışması ve sonuçlarının değerlendirilmesiyle birlikte uygulama bölümünde, sansürlü veri içeren karbon fiberlere ilişkin gerçek veriler için en uygun dağılım belirlenip, bu dağılıma ait parametre tahmincileri bulunmuştur. Dördüncü bölümde ise çalışmanın sonuçları değerlendirilmiştir.

\section{Materyal ve Metot}

Yaşam analizi sadece sağlık alanında kullanılan, ölüm veya hayatta kalma süreleri ile ilgilenen hastalık ve yaşamı etkileyen faktörleri inceleyen bir yöntem değildir. Bozulma, çürüme, ölme, başarısızlık riski taşıyan ve kullanıma bağlı olarak dayanma süreleri farklılaşan materyallerin bozulma zamanlarının analizlerinde de yararlanılmaktadır. $\mathrm{Bu}$ nedenle sadece tıp değil, ekonomi, işletme, mühendislik, sosyoloji, zooloji, botanik veya fabrikanın devamlılığı, bir makinenin bozulma zamanına kadar geçen sürenin analizleri gibi birçok farklı alanda kullanılabilen bir analiz yöntemidir. Yaşam analizinde kullanılan başarısızlık terimi, incelenen konunun denekte görülmesi durumudur. Canlılar için genelde ölüm veya hastalık, mekanik aletler için ise bozulma anlamina gelmektedir (Nelson, 1982). Yaşam analizlerinde sağkalım süresi tam olarak bilinmeyen vakalar sansürlü gözlem olarak adlandırılmaktadır. İlerleyen tür tip II sansürleme, sansürlenmiş veri çalışmalarında en popüler sansürleme şemalarından biridir. $\mathrm{Bu}$ sansürleme modelinde, $n$ sayıda özdeş bileşenin sağkalım analizine tabi tutulduğu düşünülsün. Sistemde meydana gelen 1 . bozulma ile rasgele $R_{1}$ sayıda bileşenin sistemden çekildiğini, daha sonra geriye kalan $n-R_{1}-1$ bileşenden, 2 . bozulma ile rasgele $R_{2}$ sayıda bileşenin sistemden çekildiğini ve böylece $m$. bozulma ile rasgele $R_{m}$ sayıda bileşenin sistemden çekilmesiyle $\mathrm{m}$ bileşenin bozulma zamanı gözlenir. $\mathrm{Bu}$ şekilde elde edilen $m$ hacimli örneklem ilerleyen tür tip-II sağdan sansürlü örneklemdir. Burada $n=m+\sum_{i=1}^{m} R_{i}$ 'dir. Bu durumda, $\left(R_{1}, R_{2}, R_{3}, \ldots, R_{m}\right) \quad$ sansürleme şeması ve $\left(X_{1}, X_{2}, X_{3}, \ldots, X_{m}\right)$ 'e gözlenen veriler denilir (Balakrishnan ve Aggarwala 2000). Bu sansürleme şeması Şekil 1'de gösterilmiştir:

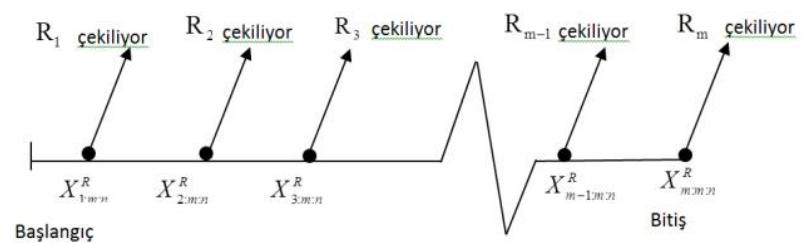

Şekil 1. İlerleyen tür tip-II sağdan sansürleme şeması

$X_{1: m: n}^{R}<X_{2: m: n}^{R}<\ldots<X_{m: m: n}^{R}$, olasıllk yoğunluk fonksiyonu $\mathrm{f}(\mathrm{x})$ ve dağ $\mathrm{llım}$ fonksiyonu $\mathrm{F}(\mathrm{x})$ olan dağılımdan alınan ilerleyen tür tip-II sağdan sansürlü örneklem olmak üzere $X_{1: m: n}^{R}<X_{2: m: n}^{R}<\ldots<X_{m: m: n}^{R}$ 'nin ortak olasilık yoğunluk fonksiyonu; 


$$
f_{X_{1: m n}^{R}, \ldots, X_{2 m n n}^{R}, \ldots, X_{m m n n}^{R}}\left(x_{1}, x_{2}, \ldots, x_{m}\right)=a \prod_{i=1}^{m} f\left(x_{i}\right)\left[1-F\left(x_{i}\right)\right]^{R_{i}},-\infty<x_{1}<x_{2}<\ldots<x_{m}<\infty
$$

şeklinde ifade edilir. Burada a sabiti,

$a=n\left(n-R_{1}-1\right) x \ldots x\left(n-R_{1}-R_{2}-\ldots-R_{m-1}-m+1\right)$ 'dir.

İlerleyen tür tip-II sağdan sansürlü örnekleme, yaşam zamanı analizlerinde veri elde etmede önemli bir yöntemdir, deneyin maliyet ve deney süresinin azaltılmasinı sağlar (Balakrishnan ve Aggarwala, 2000).

Burr dağılım ailesi, Burr (1942) tarafından yaşam süreleri verilerini modelleyebilmek için kullanılan on iki birikimli dağılım fonksiyonunu içeren bir dağılım ailesi olarak önerilmiştir. Bu ailenin en önemli iki üyesi: Burr tipi III dağılımı ve Burr tipi XII dağılımıdır. Bu iki önemli dağılım, basit dönüşüm ile birbirleriyle ilişkilidir. Weibull, üstel lojistik, genelleştirilmiş lojistik, Gompertz, normal, aşırı değer (extreme value) dağılımı ve tekdüze dağılımlar da dâhil olmak üzere birçok standart teorik dağılımlar, Burr ailesinin özel durumları veya sinırlayıcı durumlarıdır. Burr tipi III dağılımı, Log-lojistik, Weibull, Burr tipi XII gibi kapalı formdaki dağılımlardan daha çok esnek olup, çarpıklık ve basıklık açısından daha geniş alana izin verir. Burr tipi III dağılımının $\alpha$ ve $\beta$ parametrelerinin dağılım fonksiyonu ile olasılık yoğunluk fonksiyonu aşağıdaki gibidir:

$$
\begin{aligned}
& F(x \mid \alpha, \beta)=\left(1+x^{-\beta}\right)^{-\alpha}, x>0, \alpha>0, \beta>0 \\
& f(x \mid \alpha, \beta)=\beta \alpha x^{-\beta-1}\left(1+x^{-\beta}\right)^{-\alpha-1}, x>0, \alpha>0, \beta>0 .
\end{aligned}
$$

Genel olarak, Burr tipi III dağılımına benzer şekilde parametre kestirimi yapan birçok dağılım mevcuttur. Bunlar; Gamma, Lognormal, Weibull ve Exponential dağglımlardır. $\mathrm{Bu}$ dağılımlar güvenilirlik ve kalite kontrolünde önemli bir role sahiptir. Tadikmalla (1980), Burr dağılımının farklı türleri üzerinde çalışmış ve aynı zamanda bu dağılımlar arasındaki ilişkileri incelemiştir. Son yıllarda, Rastogi ve Tripathi (2013),

$$
\ell(X ; \alpha, \beta)=c \prod_{i=1}^{m} f\left(x_{i: m: n} ; \alpha, \beta\right)\left[1-F\left(x_{i: m: n}, \alpha, \beta\right)\right]^{R_{i}}
$$

Gupta ve Kundu (2001) gibi birçok bilim adamı Burr dağılımı ve üstel dağılım ailesi üzerinde çalışarak geliştirmişlerdir. $X_{1: m: n}, X_{2: m: n}, \ldots, X_{m: m: n}$ gözlem değerleri (2) ve (3) eşitliğinde verilen dağglımdan çekilmiş ilerleyen tür tip II sansürlü gözlem değerlerini ve $R_{1}, R_{2}, \ldots, R_{m}$ de ilerleyen tür tip II sansürleme şemasını göstersin. $\mathrm{Bu}$ durumda $\alpha$ ve $\beta$ parametrelerinin olabilirlik fonksiyonu aşağıdaki gibi elde edilir. $R_{i}$

Burada, $\quad c=n(n-1)\left(n-R_{1}-1\right)\left(n-R_{1}-R_{2}-2\right) \ldots\left(n-R_{1}-R_{2}-R_{3}-\ldots-R_{m-1}-m+1\right) . \quad$ Burada, $\mathrm{R}_{\mathrm{i}}>0$ ve $\sum_{i=1}^{m} R_{i}+m=n$ 'dir.

En çok olabilirlik tahmincisini elde etmek için log-olabilirlik fonksiyonu ise, 
$\log (L(X ; \alpha, \beta))=\ell(X ; \alpha, \beta)$

$$
\begin{aligned}
& \ell(X ; \alpha, \beta)=m \log \alpha+m \log \beta+(-\beta-1) \sum_{i=1}^{m} \log \left(x_{i: m: n)}\right) \\
& +(-\alpha-1) \sum_{i=1}^{m} \log \left(1+x_{i: m: n}^{-\beta}\right)+R_{i} \sum_{i=1}^{m} \log \left[1-\left(1+x_{i: m: n}^{-\beta}\right)^{-\alpha}\right]
\end{aligned}
$$

olarak elde edilir. Elde edilen log-olabilirlik türevleri ise aşağıdaki gibidir:

fonksiyonunun $\alpha$ ve $\beta$ parametrelerine göre

$$
\begin{aligned}
\frac{\partial \ell(x ; \alpha, \beta)}{\partial \alpha}= & \frac{m}{\alpha}-\sum_{i=1}^{m} \log \left(1+x_{i: m: n}^{-\beta}\right) \\
& -R_{i} \sum_{i=1}^{m} \frac{\log \left(1-\left(1+x_{i: m: n}^{-\beta}\right)\right)\left(1-\left(1+x_{i: m: n}^{-\beta}\right)^{-\alpha}\right)}{\left(1-\left(1+x_{i: m: n}^{-\beta}\right)^{-\alpha}\right)} \\
\frac{\partial \ell(x ; \alpha, \beta)}{\partial \beta}= & \frac{m}{\beta}-\sum_{i=1}^{m} \log \left(x_{i: m: n}\right)-(\alpha+1)\left[\sum_{i=1}^{m} \frac{-x_{i: m: n}^{-\beta} \ln x_{i: m: n}}{1+x_{i: m: n}^{-\beta}}\right] \\
& +\alpha R_{i} \sum_{i=1}^{m} \frac{\left(1+x_{i: m: n}^{-\beta}\right)^{-(\alpha+1)}\left(-x_{i: m: n}^{-\beta} \ln x_{i: m: n}\right)}{\left(1-\left(1+x_{i: m: n}^{-\beta}\right)^{-\alpha}\right)}
\end{aligned}
$$

Burada, $\frac{\partial \ell(\mathrm{x} ; \alpha, \beta)}{\partial \alpha}=0 \quad$ ve $\frac{\partial \ell(\mathrm{x} ; \alpha, \beta)}{\partial \beta}=0$ eşitliklerinin analitik olarak çözümlerini elde etmek mümkün olmayacaktır. $\mathrm{Bu}$ nedenle MLE tahmincilerini elde edebilmek için uygun numerik çözümlere ihtiyaç vardır. Newton-Raphson ve EM algoritması bu gibi durumlarda kullanılabilecek alternatif yöntemlerdir.

$$
\begin{aligned}
\ln [L(\theta)] & =m \ln \alpha+m \ln \beta-(\beta+1) \sum_{j=1}^{m} \ln \left(x_{j: m: n}\right) \\
& -(\alpha+1) \sum_{j=1}^{m} \ln \left(1+x_{j: m: n}^{-\beta}\right)-\alpha \sum_{j=1}^{m} R_{j}\left(\ln \left(1+x_{j: m: n}^{-\beta}\right)\right)
\end{aligned}
$$

Buradan,

$$
\begin{aligned}
& \frac{\partial^{2} \ln [L(\alpha, \beta)]}{\partial \alpha^{2}}=m\left(\frac{-1}{\alpha^{2}}\right) \\
& \frac{\partial^{2} \ln [L(\alpha, \beta)]}{\partial \beta^{2}}=m\left(\frac{-1}{\beta^{2}}\right)-(\alpha+1) \sum_{j=1}^{m} \frac{x^{-\beta} \ln x_{j: m: n} \ln \left(x^{-\beta}\right)}{\left(1+x^{-\beta}\right)}
\end{aligned}
$$




$$
\begin{aligned}
& -(\alpha+1) \sum_{j=1}^{m} \frac{x^{-\beta} \ln x_{j: m: n}}{1+x^{-\beta}}+(\alpha+1) \sum_{j=1}^{m} \frac{x^{-\beta^{2}} \ln \left(x^{-\beta}\right) \ln (x)}{\left(1+x^{-\beta}\right)^{2}} \\
& -\alpha \sum_{j=1}^{m} R_{j} \frac{x^{-\beta} \ln x_{j: m: n} \ln \left(x_{j: m: n}^{-\beta}\right)}{1+x_{j: m: n}^{-\beta}}-\alpha \sum_{j=1}^{m} R_{j} \frac{x_{j: m: n}^{-\beta} \ln x_{j: m: n}}{1+x_{j: m: n}^{-\beta}} \\
& +\alpha \sum_{j=1}^{m} R_{j} \frac{x_{j: m: n}^{-\beta^{2}} \ln \left(x_{j: m: n}^{-\beta}\right) \ln \left(x_{j: m: n}\right)}{\left(1+x_{j: m: n}^{-\beta}\right)^{2}}
\end{aligned}
$$

ve

$$
\begin{aligned}
\frac{\partial^{2} \ln [L(\alpha, \beta)]}{\partial \alpha \partial \beta} & =-\left(\sum_{j=1}^{m}\left(-\frac{x_{j: m: n}^{-\beta} \ln \left(x_{j: m: n}\right)}{1+x_{j: m: n}^{-\beta}}\right)\right) \\
& -R_{j}\left[\sum_{j=1}^{m}\left(-\frac{x_{j: m: n}^{-\beta} \ln \left(x_{j: m: n}\right)}{1+x_{j: m: n}^{-\beta}}\right)\right]
\end{aligned}
$$

\subsection{EM Algoritması}

EM algoritmas1, sansürlü veri problemlerinde parametre tahminini hesaplamak için en çok olabilirlik tahminlerini içeren yinelemeli bir yöntemdir. EM algoritması, gözlenen ve sansürlü verilere göre oluşturulan olabilirlik fonksiyonundan yola çıkmaktadır (Dempster, Laird ve Rubin, 1977). EM türündeki algoritmalarla ilk çalışmalar 1886 yılına dayanmaktadır. Ardından, McKendrick (1926) tarafindan, algoritmalar medikal alanda uygulanmaya başlanmıştır. Fesler ve Hero (1994), iki genel EM (General EM, GEM) tanımlamışlardır. EM algoritması tanındıktan sonra çok fazla alanda uygulanmıştır. EM algoritması iki aşamalı olup, E: beklenti adımı ve M: maksimizasyon adımını içerir. E-Adımı: Sansürlü veya gözlemlenemeyen veriler için beklenen değerleri yardımıyla bir bilgi elde ederken, M-Adımı: Gözlemlenen veri ve beklenen değer bilgileri altında olabilirlik fonksiyonunu maksimize eder. İlerleyen tür tip II sansürlü örneklemlerde kayıp veri ya da eksik veri sorunlarını yaşayan örneklemler olduğundan, burada bilinmeyen $\alpha$ ve $\beta$ parametrelerinin MLE' sini elde edebilmek için EM yönteminden yararlanılacaktır.

\section{E adımı:}

$\mathrm{X}_{(\mathrm{i})}$, i. zamandaki başarısızlık veya gözlemlenen veri, $R_{i}$ ise, $i$. başarısızlıktan sonra deneyden çıkarılan gözlemlenemeyen sansürlü verilerin sayısını göstersin. Böylelikle $\mathbf{X}$ gözlem vektörü, $\mathbf{X}=\left(X_{1: m: n}, X_{2: m: n}, \ldots, X_{m: m: n}\right)$ ve $\mathbf{Z}$ sansürlü gözlemler vektörü, $\mathbf{Z}_{j}=\left(Z_{j 1}, Z_{j 2}, \ldots, Z_{j m}\right)$, $j=1,2, \ldots, m$ olarak ifade edilir. Burada $Z_{j}$, $1 \times \mathrm{R}_{\mathrm{j}}$, lik bir vektörü ifade etmektedir. $\mathbf{X}$ gözlemlenen, $\mathbf{Z}$ ' de sansürlü verileri göstermek üzere tüm verileri $\mathbf{W}=(\mathbf{X}, \mathbf{Z})$ biçiminde belirtebiliriz. Tüm veriler $\mathbf{W}$ için log-olabilirlik fonksiyonu aşağıdaki gibi ifade edilir.

$$
\begin{gathered}
\lambda(\mathbf{W} ; \alpha, \beta)=n \ln \alpha+n \ln \beta-(\beta+1) \sum_{j=1}^{m} \ln x_{j: m: n}-(\alpha+1) \sum_{j=1}^{m} \ln \left(1+x_{j: m: n}^{-\beta}\right) \\
-(\beta+1) \sum_{j=1}^{m} \sum_{k=1}^{R_{j}} \ln z_{j k}-(\alpha+1) \sum_{j=1}^{m} \sum_{k=1}^{R_{j}} \ln \left(1+z_{j k}^{-\beta}\right)
\end{gathered}
$$

$\mathrm{E}\left(\mathrm{Z}_{\mathrm{jk}} \mid \mathrm{Z}_{\mathrm{jk}}>\mathrm{x}_{(\mathrm{j})}\right) \quad$ beklenen değerini

bulabilmek için, Teorem 1'den yararlanılır. 
Teorem 1: Verilen $X_{(1)}=x_{1}, \ldots, X_{(j)}=x_{(j)}$ $\mathrm{k}=1, \ldots, \mathrm{R}_{\mathrm{j}}$ için aşağıdaki gibidir. değerleri için $\mathrm{Z}_{\mathrm{jk}}$ ' nın koşullu olasılığı her

$$
\begin{aligned}
f_{z 1 x}( & \left.z_{j} \mid X_{(1)}=x_{(1)}, X_{(2)}=x_{(2)}, \ldots, X_{(j)}=x_{(j)}\right) \\
= & f_{z 1 x}\left(Z_{j} \mid X_{(j)}=x_{(j)}\right) \\
= & \frac{f\left(Z_{j} \mid \alpha, \beta\right)}{\left[1-F\left(X_{(j)} \mid \alpha, \beta\right)\right]}
\end{aligned}
$$

$\mathrm{Z}_{(\mathrm{j})}>\mathrm{x}_{(\mathrm{j})} \quad$ olduğu durumlarda. Diğer olduğu çalışmadan yararlanılabilir. Teorem durumlarda ise, eşitliğin değeri 0 ' dır. $1^{\prime} \quad i \quad$ kullanarak $E\left[\left(\ln Z_{j k} \mid Z_{j k}>x_{j}\right)\right]$ ' 1 Teoremin ispatı ile ilgili olarak detaylı bilgi aşağıdaki şekilde yazabiliriz. için Ng ve diğerlerinin 2002 yılında yapmış

$$
\begin{gathered}
E\left[\ln Z_{j k} \mid Z_{j k}>x_{j}\right]=\frac{\alpha \beta}{1-F_{x}\left(x_{j} ; \alpha, \beta\right)} \int_{x j}^{\infty} \ln u u^{-(\beta+1)}\left(1+u^{-\beta}\right)^{-(\alpha+1)} d u \\
=\frac{\alpha}{\beta\left[1-F_{x}\left(x_{j} ; \alpha, \beta\right)\right]} \int_{1}^{1+x_{j}^{-\beta}} v^{-(\alpha+1)} \ln (v-1) d v \\
=A\left(x_{j} ; \alpha_{(j)}, \beta_{(j)}\right)
\end{gathered}
$$

ve,

$$
\begin{gathered}
E\left(\ln \left(1+Z_{j k}^{-\beta}\right) \mid Z_{j k}>x_{j}\right)=\frac{\alpha \beta}{1-F_{x}\left(x_{j} ; \alpha, \beta\right)} \int_{x_{j}}^{\infty} \ln \left(1+u^{-\beta}\right) u^{-(\beta+1)}\left(1+u^{-\beta}\right)^{-(\alpha+1)} d u \\
=\frac{\alpha}{1-F_{x}\left(x_{j} ; \alpha, \beta\right)} \int_{1}^{1+x_{j}^{-\beta}} v^{-(\alpha+1)} \ln (v) d v \\
=B\left(x_{j} ; \alpha_{(i)}, \beta_{(i)}\right)
\end{gathered}
$$

\section{M adımı:}

$\mathrm{Bu}$ adımda, $\mathrm{E}[\log (\mathrm{L}(\mathrm{x} ; \boldsymbol{\alpha}, \beta))]$ beklenen değeri bilinmeyen parametreler $\alpha$ ve $\beta$, ya göre türevi alınarak maksimize edilir. $\alpha$ ve $\beta$ parametrelerinin tahmincileri aşağıdaki gibi elde edilir:

$$
\begin{aligned}
& \hat{\alpha}=\frac{n}{\sum_{j=1}^{m} \log \left(n+x_{j}^{-\beta}\right)+\sum_{j=1}^{m} R_{j} B\left(x_{j} ; \alpha, \beta\right)} \\
& \hat{\beta}=\frac{n}{\sum_{j=1}^{m} \log x_{j}-(\alpha+1) \sum_{j=1}^{m} \frac{x_{j}^{-\beta}}{\left(1+x_{j}^{-\beta}\right)}+\sum_{j=1}^{m} R_{j} A\left(x_{j} ; \alpha, \beta\right)}
\end{aligned}
$$

Burada,

$$
A\left(x_{j} ; \alpha, \beta\right)=E\left[\log Z_{j k} \mid Z_{j k}>x_{j}\right]
$$




$$
=\frac{\alpha \beta}{1-\left(1+x_{j}^{-\beta}\right)^{-\alpha}} \int_{x_{j}}^{\infty} x^{-\beta-1}\left(1+x^{-\beta}\right)^{-(\alpha+1)} \log x d x
$$

ve

$$
\begin{aligned}
B\left(x_{j} ; \alpha, \beta\right) & =E\left[\log \left(1+Z_{j k}^{-\beta}\right) \mid Z_{j k}>x_{j}\right] \\
& =\frac{\alpha \beta}{1-\left(1+x_{j}^{-\beta}\right)^{-\alpha}} \int_{x_{j}}^{\infty} x^{-(\beta+1)}\left(1+x^{-\beta}\right)^{-(\alpha+1)} \log \left(1+x^{-\beta}\right) d x \text { 'dir. }
\end{aligned}
$$

Yukarıda verilen eşitlikler fixed point yöntemiyle elde edilir. EM algoritmasının uygulama adımları ise aşağıda verilmiştir.

Adım 1: $\alpha_{0}$ ve $\beta_{0}$ başlangıç değerlerini seç.

Adım 2: Örneklemleri kullanarak $\alpha_{i}$ ve $\beta_{i}$, nin beklenen değerlerini hesapla.

Adım 3: Beklenen değerleri $\alpha$ ve $\beta$ 'ya göre maksimize et.

Adım 4: Adım 3'te ki değerleri $\alpha_{i+1}$ ve $\beta_{i+1}$ 'e ata.

Adım 5: Algoritmayı durdurma kriteri değerini elde edinceye kadar tekrar et.

$\mathrm{I}_{X}(\theta)=\mathrm{I}_{W}(\theta)-\mathrm{I}_{W \backslash X}(\theta)$

$\mathbf{X}$ :gözlemlenen veriyi, $\mathbf{W}$ :tüm verileri, $\boldsymbol{\theta}=(\alpha, \beta)$ :parametre vektörünü, $\mathrm{I}_{\mathrm{X}}(\theta)$ : gözlemlenen bilgiyi, $I_{W}(\theta)$ :bütün verilerden

$$
\mathrm{I}_{W}(\theta)=-E\left[\frac{\partial^{2} L(W ; \theta)}{\partial \theta^{2}}\right]
$$

j. başarısızlıkta tek bir sansürlü gözlem için $I_{w x x}^{(j)}(\theta)$ Fisher bilgisi aşağıda verilmiştir.

$\mathrm{I}_{W \backslash X}^{(j)}(\theta)=-E_{Z_{j} \backslash x_{(j)}}\left[\frac{\partial^{2} \ln f_{Z_{j}}\left(Z_{j} \mid x_{(j)}, \theta\right)}{\partial \theta^{2}}\right]$

Tüm veriler içerisindeki kayıp/gözlenemeyen veriler için bilgi aşağıdaki eşitlikle elde edilir.

$$
\mathrm{I}_{W \backslash X}(\theta)=\sum_{j=1}^{m} R_{j} \mathrm{I}_{W \backslash X}^{(j)}(\theta)
$$

2.3 Burr Tipi III Dağılım İlerleyen Tür Tip II Sağdan Sansürlü Örneklemi İçin Fisher Bilgi Matrisi

Bölüm 2.1 ve Bölüm 2.2'de bilinmeyen parametrelerin en çok olabilirlik tahmin edicileri Newton-Raphson ve EM algoritmas1 kullanılarak elde edilmişti. $\mathrm{Bu}$ bölümde, 1982 y1lında Louis'in kayı bilgi yönteminden yararlanılarak gözlenen Fisher bilgi matrisi elde edilecek ve parametrelerin asimptotik güven aralıkları kayıp değer prensibine dayalı Fisher bilgi matrisi aracılığıyla bulunacaktır. (Louis, 1982) aşağıda verilen ifadeye dayanmaktadır.

elde edilen bilgiyi ve $\mathrm{I}_{\mathrm{w} \backslash \mathrm{x}}(\theta)$ ise, kayı/gözlenemeyen bilgiyi göstersin.

Burada, $I_{W}(\theta)$ aşağıda verilen eşitlikle elde edilir. 
Bütün verilerden elde edilen $I_{w}(\theta)$ bilgi matrisinin elemanları aşağıdaki biçimde gösterilebilir.

$\mathrm{I}_{W}(\theta)=\left[\begin{array}{l}a_{11} a_{12} \\ a_{21} a_{22}\end{array}\right]$

Burada,

$a_{11}=\frac{n}{\alpha^{2}}$,

$a_{12}=a_{21}=\frac{n \alpha}{\beta} \int_{1}^{\infty}(u-1) \ln (u-1) u^{-(\alpha+2)} d u$

ve

$a_{22}=\frac{n}{\beta^{2}}+\frac{n \alpha(\alpha+1)}{\beta^{2}} \int_{1}^{\infty}(u-1)\{\ln (u-1)\}^{2} u^{-(\alpha+3)} d u$, olacaktır.

(17) eşitliğinde verilen tüm beklenen bilgi matrisi $\mathrm{I}_{w \mathrm{x}}^{(\mathrm{j})}(\theta)$, aşağıda belirtildiği gibi değerlerin hesaplanmasının ardından kayıp elde edilir.

$\mathrm{I}_{W \backslash X}^{(j)}(\theta)=\left[\begin{array}{l}b_{11}\left(x_{(j)} ; \alpha, \beta\right) b_{12}\left(x_{(j)} ; \alpha, \beta\right) \\ b_{21}\left(x_{(j)} ; \alpha, \beta\right) b_{22}\left(x_{(j)} ; \alpha, \beta\right)\end{array}\right]$

Burada,

$$
\begin{aligned}
b_{11}\left(x_{(j)} ; \alpha, \beta\right) & =\frac{1}{\alpha^{2}}-\frac{\left(1+x^{-\beta}\right)^{-\alpha}\left[\ln \left(1+x^{-\beta}\right)\right]^{2}}{\left[1-\left(1+x^{-\beta}\right)^{-\alpha}\right]^{2}} \\
b_{12}\left(x_{(j)} ; \alpha, \beta\right) & =b_{21}\left(x_{(j)} ; \alpha, \beta\right) \\
& =\frac{\alpha}{\beta\left[1-F\left(x_{j} ; \alpha, \beta\right)\right]} \int_{1}^{1+x_{j}^{-\beta}}(u-1) \ln (u-1) u^{-(\alpha+2)} d u \\
& -\frac{\alpha x_{j}^{-\beta}\left(1+x_{j}^{-\beta}\right)^{-(\alpha+1)} \ln \left(x_{j}\right)}{\beta\left[1-F\left(x_{j} ; \alpha, \beta\right)\right]^{2}}\left[1-\left(1+x_{j}^{-\beta}\right)^{-\alpha}-\alpha \ln \left(1+x_{j}^{-\beta}\right)\right]
\end{aligned}
$$

ve

$b_{22}=\frac{1}{\beta^{2}}-k_{1}\left(x_{(j)} ; \alpha, \beta\right)-k_{2}\left(x_{(j)} ; \alpha, \beta\right)$,

$k_{1}\left(x_{(j)} ; \alpha, \beta\right)=\frac{\alpha}{\beta^{2}\left[1-F\left(x_{j} ; \alpha, \beta\right)\right]} \int_{1}^{1+x_{j}^{-\beta}}(u-1)\{\ln (u-1)\}^{2} u^{-(\alpha+3)} d u$

$k_{2}\left(x_{(j)} ; \alpha, \beta\right)=\frac{\alpha x_{j}^{-\beta}\left(1+x_{j}^{-\beta}\right)^{-(\alpha+2)} \ln \left(x_{(j)}\right)}{\beta\left[1-F\left(x_{j} ; \alpha, \beta\right)\right]^{2}}\left[\left(1+x_{j}^{-\beta}\right)^{-\alpha}-1+\alpha x_{j}^{-\beta}\right]$,

olarak elde edilir. 
Böylece, gözlemlenen bilgi matrisi $\mathrm{I}_{\mathrm{X}}(\theta)$ yukarıda belirtilen iki matrisin kullanılmasıyla hesaplanır. $\alpha$ ve $\beta$ parametrelerinin MLE'nin asimptotik varyans-kovaryans matrisi ise $\mathrm{I}_{\mathrm{x}}^{-1}(\hat{\alpha}, \hat{\beta})$ olarak elde edilecektir. MLE'nin asimptotik özelliğinin kullanılmasıyla $\frac{\hat{\alpha}-\alpha}{\sqrt{\operatorname{Var}(\hat{\alpha})}}$ ve

\section{Bulgular}

\subsection{Benzetim Çalışması ve Sonuçları}

$\mathrm{Bu}$ bölümde, önerilen parametre tahmincilerinin performanslarını karşılaştırmak amacıyla, Monte Carlo benzetim çalı̧̧ması $\mathrm{R}$ 3.1.3 programı kullanılarak gerçekleştirilmiş̧ir. İlerleyen tür tip II sağdan sansürlü örneklemin Burr tipi III dağılımı için, farklı parametre büyüklüklerinde, farklı örneklem genişliklerinde ve çeşitli sansürleme şemaları altında benzetim çalışması oluşturulmuştur. Her aşamada $\alpha$ ve $\beta$ ' nın en çok olabilirlik tahmincileri Newton Raphson ve EM
$\frac{\hat{\beta}-\beta}{\sqrt{\operatorname{Var}(\hat{\beta})}}$ nın $\quad$ yaklaşık olarak standart normal dağıldı ı̆ını söyleyebiliriz. Bu özellik ile, $\alpha$ ve $\beta$ ' nın $100(1-\tau) \%$ güven aralığı ise $\hat{\alpha} \pm Z_{\tau / 2} \sqrt{\operatorname{Var}(\hat{\alpha})}$ ve

$\hat{\beta} \pm \mathrm{Z}_{\tau / 2} \sqrt{\operatorname{Var}(\hat{\beta})}$, ifadelerinden elde edilir.

algoritması ile elde edilmiş olup bu parametre tahminleri her bir adımın $1000 \mathrm{kez}$ tekrarından elde edilen değerlerle bulunmuştur. Benzetim çalışmasında $\alpha$ ve $\beta$ parametrelerinin sadece tahmin değerleri değil aynı zamanda her bir tahmine ilişkin en küçük kareler ortalaması değerleri ve $\% 95$ güven aralığında Fisher bilgi matrisi kullanılarak, parametrelere ilişkin güven aralıkları oluşturulmuştur. Benzetim çalışması için seçilen farklı büyüklüklerde ki $\alpha$ ve $\beta$ parametre çiftlerinin değerleri Tablo 1 'de verilmiştir.

Tablo 1. $(\boldsymbol{\alpha}, \boldsymbol{\beta})$ değerleri

$\begin{array}{lllllll}(\boldsymbol{\alpha}, \boldsymbol{\beta}) & (0.5,1) & (0.5,1.5) & (1,2) & (1,2.5) & (2,2.5) & (2,3)\end{array}$

Benzetim çalışmasında, her bir $(\alpha, \beta)$ olarak seçilmiş olup, Burr tipi III dağılımın parametre çifti için, rasgele olarak türetilen ilerleyen tür tip II sağdan sansürlü örneklem ilerleyen tür tip II sağdan sansürlü örneklem şemaları ise Tablo 2'de verilmiştir. büyüklükleri değerleri ise $\mathrm{n}=20,30,50$ ve 60

Tablo 2. Burr Tipi III Dağılımın İlerleyen Tür Tip II Sağdan Sansürlü Örneklem Şemaları

\begin{tabular}{ccc}
\hline $\mathbf{n}$ & $\mathbf{m}$ & $\mathbf{R}$ (Sansürleme Şeması) \\
\hline 20 & 15 & $\left(5,0^{* 14}\right)$ \\
30 & 20 & $\left(10,0^{* 19}\right)$
\end{tabular}




\begin{tabular}{lll}
50 & 35 & $\left(15,0^{* 34}\right)$ \\
60 & 40 & $\left(20,0^{* 39}\right)$ \\
\hline
\end{tabular}

Tablo 2'de verilen sansürleme şemasında seçilmediğini ifade etmektedir. Benzetim $R=\left(5,0^{* 14}\right)$ gösterimi, 1 . başarısızlık çalışması sonucunda, parametre tahminleri gerçekleştiğinde örneklemden rasgele olarak $R_{1}=5$ gözlemin çekildiğini, $x_{2}, \ldots, x_{15}$ başarısızlıklar gerçekleştiğinde ise, için kullanılan Newton Raphson yöntemi ve EM algoritmasından elde edilen sonuçlar, Tablo 3 - Tablo 8 verilmektedir. $R_{2}=0, \ldots, R_{15}=0 \quad$ gösterimi ile $\quad \mathrm{de}$ örneklemden rasgele gözlemlerin

Tablo 3. $\alpha=\mathbf{0 . 5}$ ve $\beta=1$ için, Newton Raphson-EM Algoritması Sonuçları

\begin{tabular}{|c|c|c|c|c|c|c|c|}
\hline \multirow[b]{2}{*}{$\mathbf{n}$} & \multirow[b]{2}{*}{$\mathbf{m}$} & \multirow[b]{2}{*}{$\mathbf{R}$} & & \multicolumn{2}{|c|}{ NR } & \multicolumn{2}{|c|}{ EM } \\
\hline & & & & $\hat{\alpha}(\mathrm{MSE})$ & $\hat{\beta}$ (MSE) & $\hat{\alpha}(\mathrm{MSE})$ & $\hat{\beta}(\mathrm{MSE})$ \\
\hline 20 & 15 & $\left(5,0^{* 14}\right)$ & & $0.3984(0.2135)$ & $0.4798(0.2204)$ & $0.5278(0.0112)$ & $1.0236(0.031)$ \\
\hline & & & $\mathrm{CI}$ & $(0.2714-0.5628)$ & $(0.3149-0.6971)$ & $(0.4916-0.6317)$ & $(0.9305-1.2484)$ \\
\hline 30 & 20 & $\left(10,0^{* 19}\right)$ & & $0.3035(0.7246)$ & $0.5805(0.3172)$ & $0.5172(0.0193)$ & $1.1006(0.0126)$ \\
\hline & & & $\mathrm{CI}$ & $(0.2973-0.3096)$ & $(0.5743-0.5866)$ & $(0.5110-0.5233)$ & $(1.094-1.1067)$ \\
\hline 50 & 35 & $\left(15,0^{* 34}\right)$ & & $0.3769(0.4426)$ & $0.6386(0.3678)$ & $0.5117(0.0015)$ & $1.1609(0.0208)$ \\
\hline & & & $\mathrm{CI}$ & $(0.3737-0.3800)$ & $(0.5977-0.6794)$ & $(0.5085-0.5148)$ & $(1.1200-1.2017)$ \\
\hline 60 & 40 & $\left(20,0^{* 39}\right)$ & & $0.4227(0.2201)$ & $0.7665(0.2722)$ & $0.5057(0.0167)$ & $1.1288(0.0167)$ \\
\hline & & & $\mathrm{CI}$ & $(0.4141-0.4312)$ & $(0.7179-0.8150)$ & $(0.4971-0.5142)$ & $(1.0802-1.1773)$ \\
\hline
\end{tabular}

Tablo 4. $\alpha=0.5$ ve $\beta=1.5$ için, Newton Raphson-EM Algoritması Sonuçları

\begin{tabular}{|c|c|c|c|c|c|c|c|}
\hline \multirow[b]{2}{*}{$\mathbf{n}$} & \multirow[b]{2}{*}{$\mathbf{m}$} & \multirow[b]{2}{*}{$\mathbf{R}$} & & \multicolumn{2}{|c|}{ NR } & \multicolumn{2}{|c|}{ EM } \\
\hline & & & & $\hat{\alpha}(\mathrm{MSE})$ & $\hat{\beta}$ (MSE) & $\hat{\alpha}(\mathrm{MSE})$ & $\hat{\beta}$ (MSE) \\
\hline \multirow[t]{2}{*}{20} & 15 & $\left(5,0^{* 14}\right)$ & & $0.5760(0.2703)$ & $0.4193(0.0806)$ & $0.5101(0.0422)$ & $1.5693(0.0498)$ \\
\hline & & & $\mathrm{CI}$ & $(0.6960-0.8959)$ & $(0.3981-0.4405)$ & $(0.4610-0.7103)$ & $(1.5989-1.7988)$ \\
\hline \multirow[t]{2}{*}{30} & 20 & $\left(10,0^{* 19}\right)$ & & $0.5893(0.2910)$ & $0.3552(0.1447)$ & $0.5249(0.0213)$ & $1.5527(0.0170)$ \\
\hline & & & CI & $(0.5448-0.6338)$ & $(0.3430-0.3673)$ & $(0.5216-0.675)$ & $(1.5365-1.6254)$ \\
\hline \multirow[t]{2}{*}{50} & 35 & $\left(15,0^{* 34}\right)$ & & $0.6571(0.8428)$ & $0.3393(0.1606)$ & $0.5279(0.027)$ & $1.5651(0.025)$ \\
\hline & & & $\mathrm{CI}$ & $(0.6270-0.6873)$ & $(0.3333-0.3534)$ & $(0.5192-0.6338)$ & $(1.5429-1.6471)$ \\
\hline \multirow[t]{2}{*}{60} & 40 & $\left(20,0^{* 39}\right)$ & & $0.6161(0.8838)$ & $0.3625(0.1374)$ & $0.5211(0.0617)$ & $1.5544(0.01463)$ \\
\hline & & & $\mathrm{CI}$ & $(0.5927-0.6395)$ & $(0.3566-0.3685)$ & $(0.5182-0.5994)$ & $(1.5389-1.6258)$ \\
\hline
\end{tabular}

Tablo 5. $\alpha=\mathbf{1}$ ve $\boldsymbol{\beta}=\mathbf{2}$ için, Newton Raphson-EM Algoritması Sonuçları 


\begin{tabular}{|c|c|c|c|c|c|c|c|}
\hline \multirow[b]{2}{*}{$\mathbf{n}$} & \multirow[b]{2}{*}{$\mathbf{m}$} & \multirow[b]{2}{*}{$\mathbf{R}$} & & \multicolumn{2}{|c|}{ NR } & \multicolumn{2}{|c|}{ EM } \\
\hline & & & & $\hat{\alpha}(\mathrm{MSE})$ & $\hat{\beta}(\mathrm{MSE})$ & $\hat{\alpha}(\mathrm{MSE})$ & $\hat{\beta}(\mathrm{N}$ \\
\hline \multirow[t]{2}{*}{20} & 15 & $\left(5,0^{* 14}\right)$ & & 104) & 1.9217 & $0.9855(0.0120)$ & $1.9721(0.0527)$ \\
\hline & & & $\mathrm{CI}$ & $(0.5770-()$ & $(1.8756-1.9677)$ & $(0.9230-1.0479)$ & $(1.9260-2.0181)$ \\
\hline \multirow[t]{2}{*}{30} & 20 & $\left(10,0^{* 19}\right)$ & & $0.5917(0.4082)$ & $1.9177(0.4496)$ & $0.9884(0.0390)$ & $2.1052(0.0211)$ \\
\hline & & & CI & $(0.5511-0.6322)$ & $(1.7739-2.0614)$ & $(0.9478-1.0289)$ & (1.9614 \\
\hline \multirow[t]{2}{*}{50} & 35 & $\left(15,0^{* 34}\right)$ & & $0.6442(0.3855)$ & $1.9303(0.3696)$ & $1.0370(0.0324)$ & $1.9874(0.0239)$ \\
\hline & & & $\mathrm{CI}$ & $(0.6231-0.6652)$ & $(1.8500$ & $(1.0159-1.0580)$ & $(1.907)$ \\
\hline \multirow[t]{4}{*}{60} & 40 & $\left(20,0^{* 39}\right)$ & & $0.6981(0.2746)$ & $1.9811(0.2118)$ & $1.0176(0.01237)$ & $2.0391(0.0185)$ \\
\hline & & & $\mathrm{CI}$ & (0.000 & $(1.7528$ & $(1.00$ & $(1.80$ \\
\hline & \multicolumn{7}{|c|}{ Tablo $6 \alpha=1$ ve $\beta=2.5$ için, Newton Raphson-EM Algoritması Sonuçları } \\
\hline & & & & \multicolumn{2}{|c|}{ NR } & \multicolumn{2}{|c|}{ EM } \\
\hline $\mathbf{n}$ & $\mathbf{m}$ & $\mathbf{R}$ & & $\hat{\alpha}(\mathrm{N}$ & $\hat{\beta}(\mathrm{M}$ & $\hat{\alpha}(1$ & \\
\hline \multirow[t]{2}{*}{20} & 15 & $\left(5,0^{* 14}\right.$ & & $0.5192(0.4807)$ & $2.0609(0.2391)$ & $0.9942(0.0403)$ & $2.2541(0.2382)$ \\
\hline & & & $\mathrm{Cl}$ & $(0.4817-0.5566)$ & $(1.7157-2.4060)$ & $(0.9567-1.0316)$ & $(1.9089-2.5992)$ \\
\hline \multirow[t]{2}{*}{30} & 20 & $\left(10,0^{* 19}\right)$ & & $0.6792(0.046)$ & $2.1944(0.5$ & $1.0466(0.0223)$ & $2.3765(0.2056)$ \\
\hline & & & $\mathrm{CI}$ & $(0.6380-0.7203)$ & $(2.0319-2.3568)$ & $(1.0054-1.0877)$ & $(2.2140-2.5389)$ \\
\hline \multirow[t]{2}{*}{50} & 35 & $\left(15,0^{* 34}\right)$ & & $0.7080(0.4197)$ & $2.2541(0.3801)$ & $1.0537(0.0315)$ & $2.5728(0.1885)$ \\
\hline & & & $\mathrm{CI}$ & $(0.6918-0.7241)$ & $(2.0066-2.5015)$ & $(1.0375-1.0698)$ & $(2.3253-2.8202)$ \\
\hline \multirow[t]{2}{*}{60} & 40 & $\left(20,0^{* 39}\right)$ & & $0.9386(0.3054)$ & $2.7855(0.2248)$ & $1.0195(0.0214)$ & $2.5376(0.1238)$ \\
\hline & & & $\mathrm{CI}$ & $(0.9270-0.9501)$ & $(2.5764-2.9945)$ & $(1.0079-1.0310)$ & $(2.3285-2.7466)$ \\
\hline
\end{tabular}

Tablo 7. $\alpha=2$ ve $\beta=\mathbf{2 . 5}$ için, Newton Raphson-EM Algoritması Sonuçları

\begin{tabular}{|c|c|c|c|c|c|c|c|}
\hline \multirow[b]{2}{*}{$\mathbf{n}$} & \multirow[b]{2}{*}{$\mathbf{m}$} & \multirow[b]{2}{*}{$\mathbf{R}$} & & \multicolumn{2}{|c|}{ NR } & \multicolumn{2}{|c|}{ EM } \\
\hline & & & & $\hat{\alpha}(\mathrm{MSE})$ & $\hat{\beta}(\mathrm{MSE})$ & $\hat{\alpha}(\mathrm{MSE})$ & $\hat{\beta}(\mathrm{MSE})$ \\
\hline \multirow[t]{2}{*}{20} & 15 & $\left(5,0^{* 14}\right)$ & & $1.2746(0.4575)$ & $1.8247(0.5612)$ & $1.8247(0.0888)$ & $2.4734(0.0443)$ \\
\hline & & & $\mathrm{CI}$ & $(1.1497-1.3994)$ & $(1.4936-2.1557)$ & $(1.6998-1.9495)$ & $(2.1423-2.8044)$ \\
\hline \multirow[t]{2}{*}{30} & 20 & $\left(10,0^{* 19}\right)$ & & $1.1539(0.3781)$ & $1.9204(0.4834)$ & $1.9119(0.0150)$ & $2.7446(0.0198)$ \\
\hline & & & $\mathrm{CI}$ & $(1.0761-1.2316)$ & $(1.6410-2.1997)$ & $(1.8341-1.9896)$ & $(2.4652-3.0239)$ \\
\hline \multirow[t]{2}{*}{50} & 35 & $\left(15,0^{* 34}\right)$ & & $1.5869(0.3611)$ & $1.9520(0.4174)$ & $2.0644(0.0123)$ & $2.4591(0.0532)$ \\
\hline & & & $\mathrm{CI}$ & $(1.5422-1.6315)$ & $(1.7903-2.1136)$ & $(2.0197-2.1090)$ & (2.2974-2.6207) \\
\hline \multirow[t]{2}{*}{60} & 40 & $\left(20,0^{* 39}\right)$ & & $1.7595(0.3117)$ & $1.9848(0.2813)$ & $2.0410(0.0648)$ & $2.5378(0.2695)$ \\
\hline & & & CI & $(1.7245-1.7944)$ & $(1.8749-2.0946)$ & $(2.0060-2.0759)$ & $(2.4279-2.6476)$ \\
\hline
\end{tabular}

Tablo 8. $\alpha=\mathbf{2}$ ve $\boldsymbol{\beta}=\mathbf{3}$ için, Newton Raphson-EM Algoritması Sonuçları

\begin{tabular}{|c|c|c|c|c|c|c|}
\hline \multirow[b]{2}{*}{$\mathbf{n}$} & \multirow[b]{2}{*}{$\mathbf{m}$} & \multirow[b]{2}{*}{$\mathbf{R}$} & \multicolumn{2}{|c|}{ NR } & \multicolumn{2}{|c|}{ EM } \\
\hline & & & $\hat{\alpha}(\mathrm{MSE})$ & $\hat{\beta}$ (MSE) & $\hat{\alpha}(\mathrm{MSE})$ & $\hat{\beta}(\mathrm{MSE})$ \\
\hline 20 & 15 & $\left(5,0^{* 14}\right)$ & $1.4936(0.4012)$ & $2.2815(0.4735)$ & $1.7905(0.0963)$ & $2.5766(0.0388)$ \\
\hline
\end{tabular}




\begin{tabular}{|c|c|c|c|c|c|c|c|}
\hline & & & $\mathrm{CI}$ & $(1.4235-1.5636)$ & $(1.9302-2.6327)$ & $(1.7204-1.8605)$ & $(2.2253-2.9278)$ \\
\hline \multirow{2}{*}{\multicolumn{2}{|c|}{$\begin{array}{ll}30 & 20\end{array}$}} & $\left(10,0^{* 19}\right)$ & & $99(0.3874)$ & $2.5450(0.4356)$ & $1.9572(0.0174)$ & $2.8472(0.0448)$ \\
\hline & & & $\mathrm{CI}$ & $(1.5000-1.7197)$ & $568-2.9331)$ & $(1.8473-2.0670)$ & $(2.4590-3.2353)$ \\
\hline \multirow[t]{2}{*}{50} & 35 & $\left(15,0^{* 34}\right)$ & & 1. & 36(0.4227) & 38) & $.0281(0.0321)$ \\
\hline & & & $\mathrm{CI}$ & $(1.7186-1.7965)$ & $(2.2807-2.8464)$ & $(2.0857-2.1636)$ & $(2.7452-3.3109)$ \\
\hline \multirow[t]{2}{*}{60} & 40 & $\left(20,0^{* 39}\right)$ & & $1.8913(0.3517)$ & $2.6112(0.2390)$ & $2.0297(0.0182)$ & $3.1753(0.0131)$ \\
\hline & & & $\mathrm{CI}$ & $(1.8630-1.9195)$ & $(2.4705-2.7518)$ & $(2.0014-2.0579)$ & (3.0346-3.3159) \\
\hline
\end{tabular}

Benzetim çalışmasının sonuçlarının verildiği Tablo 3 - Tablo 8 incelendiğinde, EM algoritması ile elde edilen parametre sonuçlarının Newton Raphson yönteminden çok daha iyi olduğu görülmektedir. Aynı zamanda, EM algoritması ile elde edilen parametre tahminlerine ait MSE değerleri, Newton Raphson yöntemine göre daha küçüktür. \%95 güven düzeyinde, $\mathrm{EM}$ algoritması ile elde edilen asimptotik güven aralıkları karşılaştırıldığında ise, EM aralıklarının Newton Raphson' a göre daha dar olduğu gözlemlenmiştir. Her iki güven aralığında bilinmeyen parametre değerlerini içermiş olsa da EM algoritması Newton Raphson yöntemine göre tercih edilir. Aynı zamanda tablolar incelendiğinde, farklı örneklem büyüklükleri farklı sansür şemalarına göre oluşturulan benzetim çalışması senaryolarında her iki yöntemin de örneklem genişliği arttıkça, daha tutarlı sonuçlar verdiği görülmektedir.

\subsection{Gerçek Yaşam Verisi Uygulama Örneği}

$\mathrm{Bu}$ bölümde, gerçek veri seti analiz edilmektedir. Literatürde, bu veri seti Burr tipi III dağılımı için tartışılmıştır. Bader ve Priest tarafından 1982 yılında yapılan araştırmada basit bir fiber lifinden, 1000 karbonluk fiber lifi içeren örneklerin elde edildiği veri seti kullanılmıştır. Bader ve Priest (1982), elde edilen fiber liflerinin dayanıklılığını 1,10,20 ve 50 mm'lik fiber lifi çap uzunluklarında incelemiş ve veriyi bu uzunlukları göz önüne alarak elde etmiştir. Ardından verileri 20, 50, 150 ve $300 \mathrm{~mm}$ uzunluklarında dayanıklılık testine tabi tutmuşlardır. Ölçüm uzunlukları 10 mm'lik olan tek karbon fiber lifleri için GPA'da ölçülen dayanıklılık değerlerine ilişkin veri seti aşağıdaki gibidir.

6.693, 8.432, 9.052, 9.281, 9.554, 10.486, 10.602, 10.979, 10.990, 11.531, 11.635, 11.870, $12.404,12.453,12.491,12.579,13.131,13.654,13.681,13.708,13.791,14.282,14.512$, $15.456,15.487,17.392,18.486,18.690,18.859,18.859,19.629,20.005,20.697,22.760$, 23.081, 23.220, 25.028, 25.103, 25.406, 25.610, 26.154, 26.364, 26.950, 27.994, 28.389, 
29.283, 30.205, 31.031, 32.884, 33.149, 34.364, 34.953, 35.234, 37.637, 47.087, 47.990, $48.716,53.038,55.924,56.092,68.374,81.045,151.41$

Şekil 2'de bir karbon lifinin gösterimi verilmiştir.

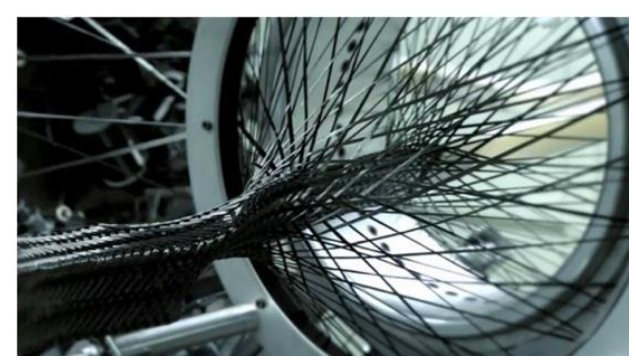

Şekil 2. Karbon Fiber Kablo Lifleri

Üzerinde çalışmış olduğumuz gerçek yaşam amacıyla; Gamma dağılım, Weibull dağılım, verisinin Burr tipi III dağılımdan gelip Log-Normal dağılım ve Üstel dağılım gelmediğinin araştırılması için, $\mathrm{R} \quad 3.1 .3$ incelenmiştir. Karşılaştırmak amacıyla programında uyum iyiliği test kodları kullanılan dağılımların olasılık yoğunluk yazılmış olup, ilgili dağılım karşılaştırmak fonksiyonları Tablo 9'da verilmiştir.

Tablo 9. Dağılımların Olasılık Yoğunluk Fonksiyonları

\begin{tabular}{cl}
\hline Dağılım & Olasılık Yoğunluk Fonksiyonu \\
\hline $\mathrm{G}(\alpha, \beta)$ & $\frac{1}{\Gamma(\alpha) \beta^{\alpha}} x^{\alpha-1} e^{\frac{-x}{\beta}}$ \\
$\mathrm{W}(\alpha, \beta)$ & $\frac{\alpha}{\beta^{\alpha}} x^{\alpha-1} e^{\left(-\frac{x}{\beta}\right)^{\alpha}}$ \\
$\log -\mathrm{N}(\alpha, \beta)$ & $\frac{1}{x \sigma \sqrt{2 \pi}} \exp \left[\frac{-(\ln x-\mu)^{2}}{2 \sigma^{2}}\right]$ \\
$\operatorname{Exp}(\alpha)$ & $\alpha e^{-\alpha x}$ \\
$\operatorname{Burr} \mathrm{III}(\alpha, \beta)$ & $\beta \alpha \mathrm{x}^{-\beta-1}\left(1+\mathrm{x}^{-\beta}\right)^{-\alpha-1}$ \\
\hline
\end{tabular}

Gamma, Weibull, Log-Normal, Üstel ve Burr Darling (AD) uyum iyiliği testleri ile Akaike tipi III dağılımlarını karşılaştırmak için (AIC) ve Bayes (BIC) uyum iyiliği uygulanan Kolmogorov-Smirnov $(\mathrm{KS})$, kriterlerine ait sonuçlar Tablo $10^{\prime} \mathrm{da}$ Cramer-von Mises (CVM), Anderson- verilmiştir.

Tablo 10 Dağılımların Uyum İyiliği Test Sonuçları

\begin{tabular}{llllllll}
\hline Dağılım & $\hat{\boldsymbol{\alpha}}$ & $\hat{\boldsymbol{\beta}}$ & KS & CVM & AD & AIC & BIC \\
\hline $\mathrm{G}(\alpha, \beta)$ & 2.4731 & 0.0935 & 0.1059 & 0.2101 & 1.3532 & 519.6326 & 523.9188 \\
\hline
\end{tabular}




\begin{tabular}{llllllll}
\hline $\mathrm{W}(\alpha, \beta)$ & 1.4298 & 29.4758 & 0.1379 & 0.2967 & 2.0354 & 528.8282 & 533.1145 \\
$\log -\mathrm{N}(\alpha, \beta)$ & 3.0593 & 0.6159 & 0.0987 & 0.0837 & 0.5698 & 507.2042 & 511.4905 \\
$\operatorname{Exp}(\alpha)$ & 0.0378 & 0.0378 & 0.2581 & 0.8697 & 5.0336 & 540.6426 & 542.7858 \\
$\operatorname{Burr} \mathrm{III}(\alpha, \beta)$ & 225.6142 & 1.9554 & 0.0886 & 0.0684 & 0.3554 & 502.4946 & 506.7809 \\
\hline
\end{tabular}

Tablo 10’ da sonuçlar incelendiğinde, açıkça olduğunu söyleyebiliriz. Dağılımları görülmektedir ki Burr tipi III dağılımının en karşılaştırmak amacıyla yapılan birikimli küçük test istatistiklerine ve aynı zamanda en dağılım fonksiyonu, histogram ve yoğunluk küçük AIC ve BIC değerlerine sahip olduğu fonksiyonları, Q-Q grafikleri ve P-P görülmektedir. Böylelikle, Burr tipi III grafikleri Şekil 3-Şekil 6'da verilmiştir. dağılımımızın veriye en uygun dağılım

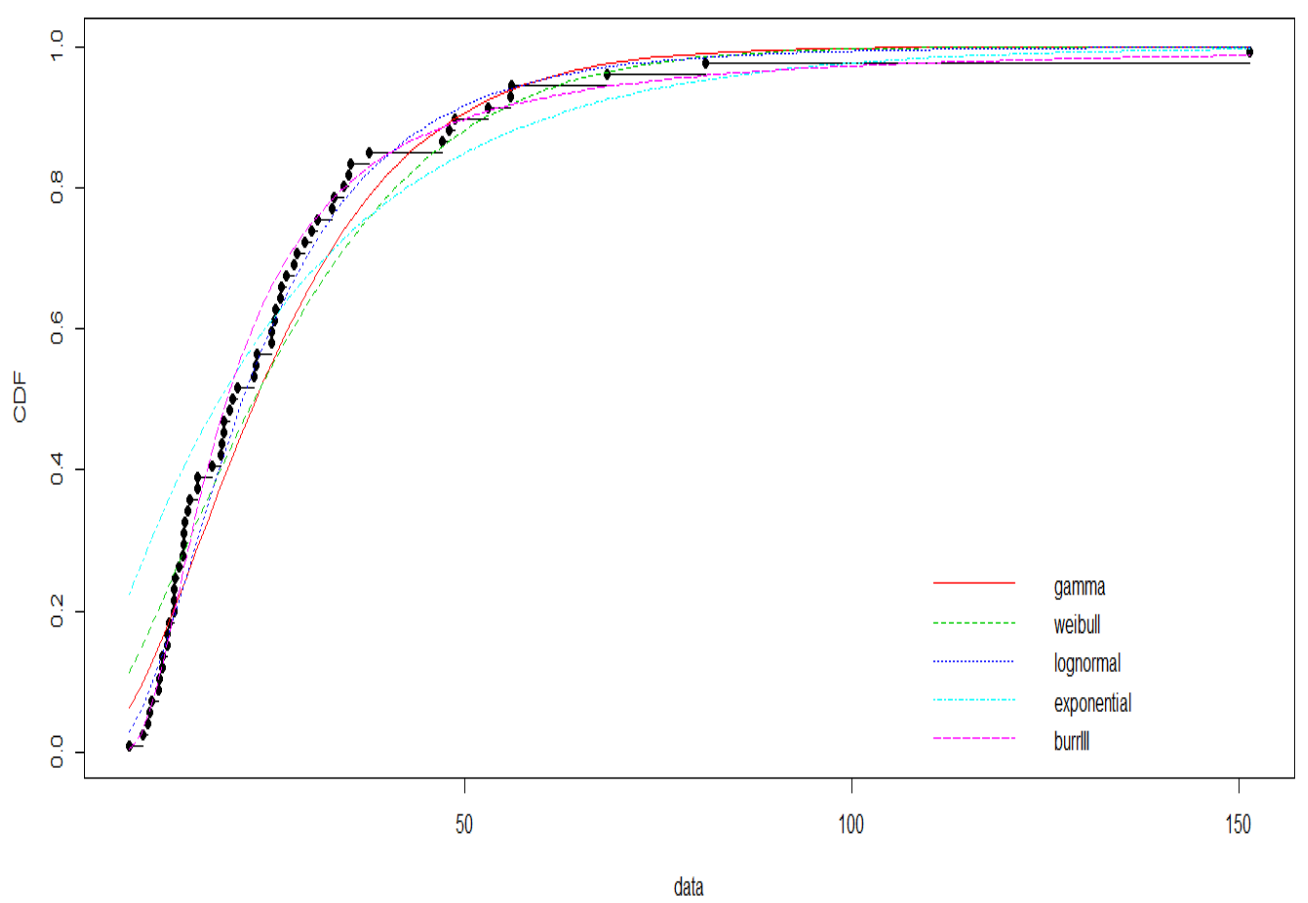

Şekil 3 Dağılımlara İlişkin Birikimli Dağılım Fonksiyonu Grafikleri 


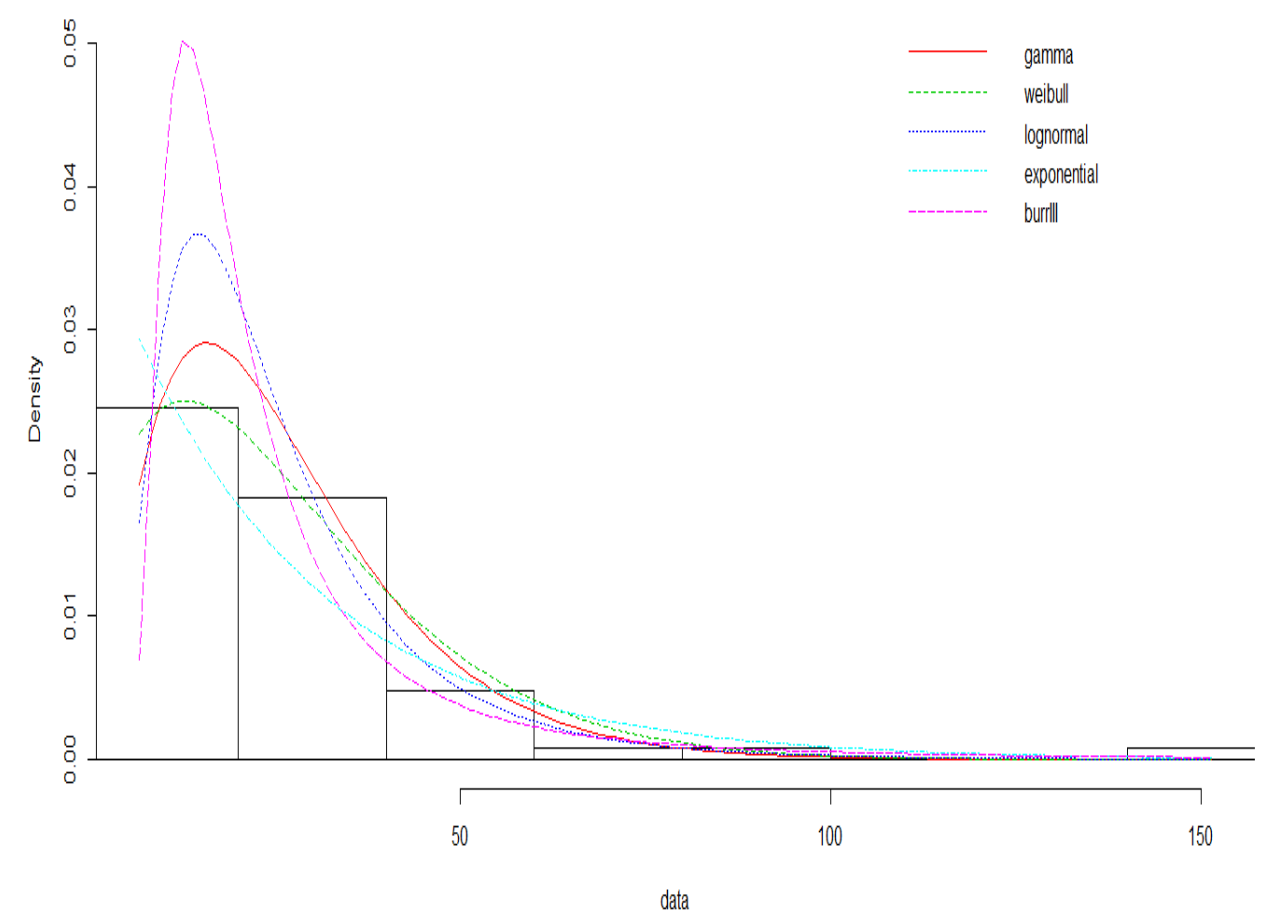

Şekil 4 Dağılımlara İlişskin Histogram ve Yoğunluk Fonksiyonu Grafikleri

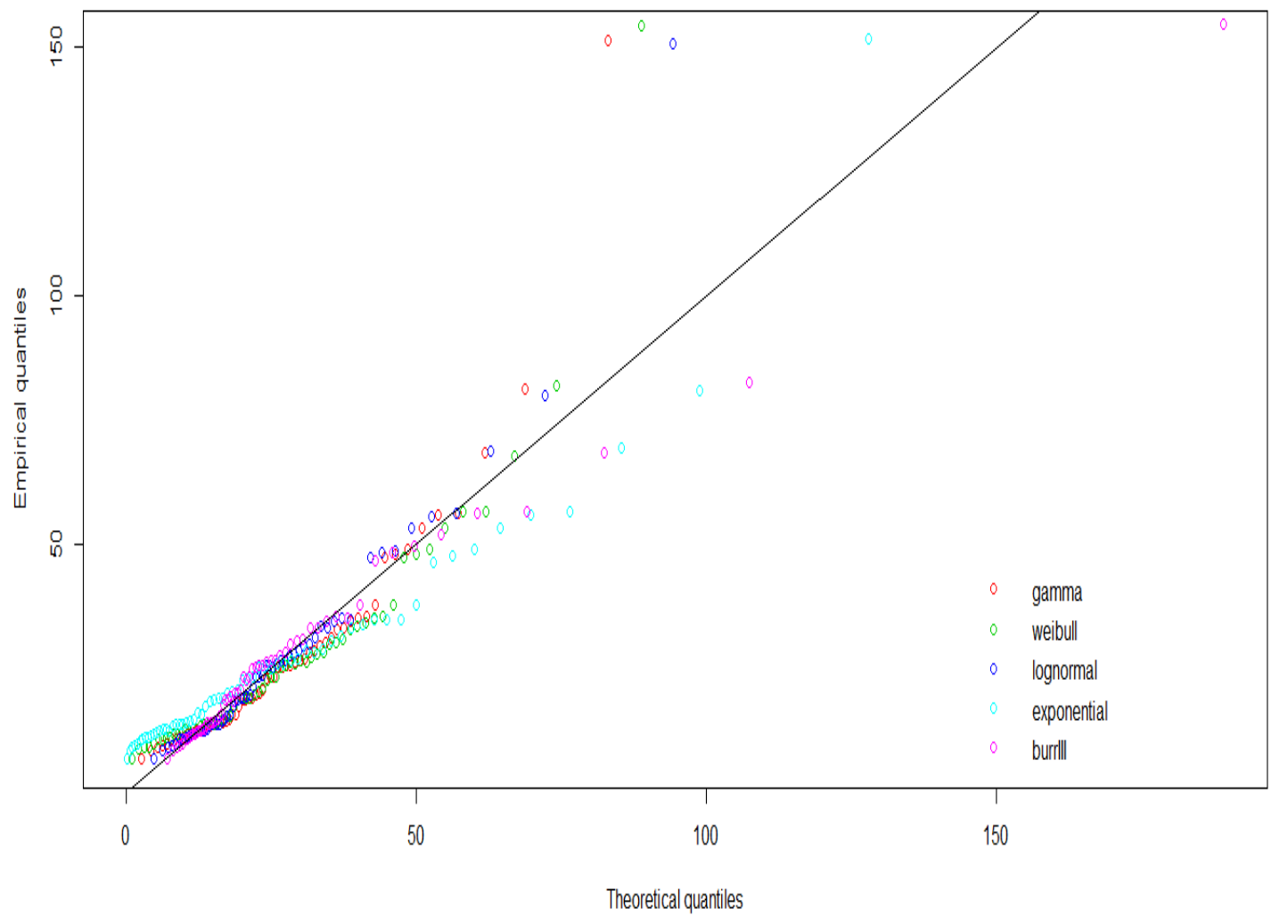

Şekil 5 Dağılımlara İlişkin Q-Q Grafikleri 


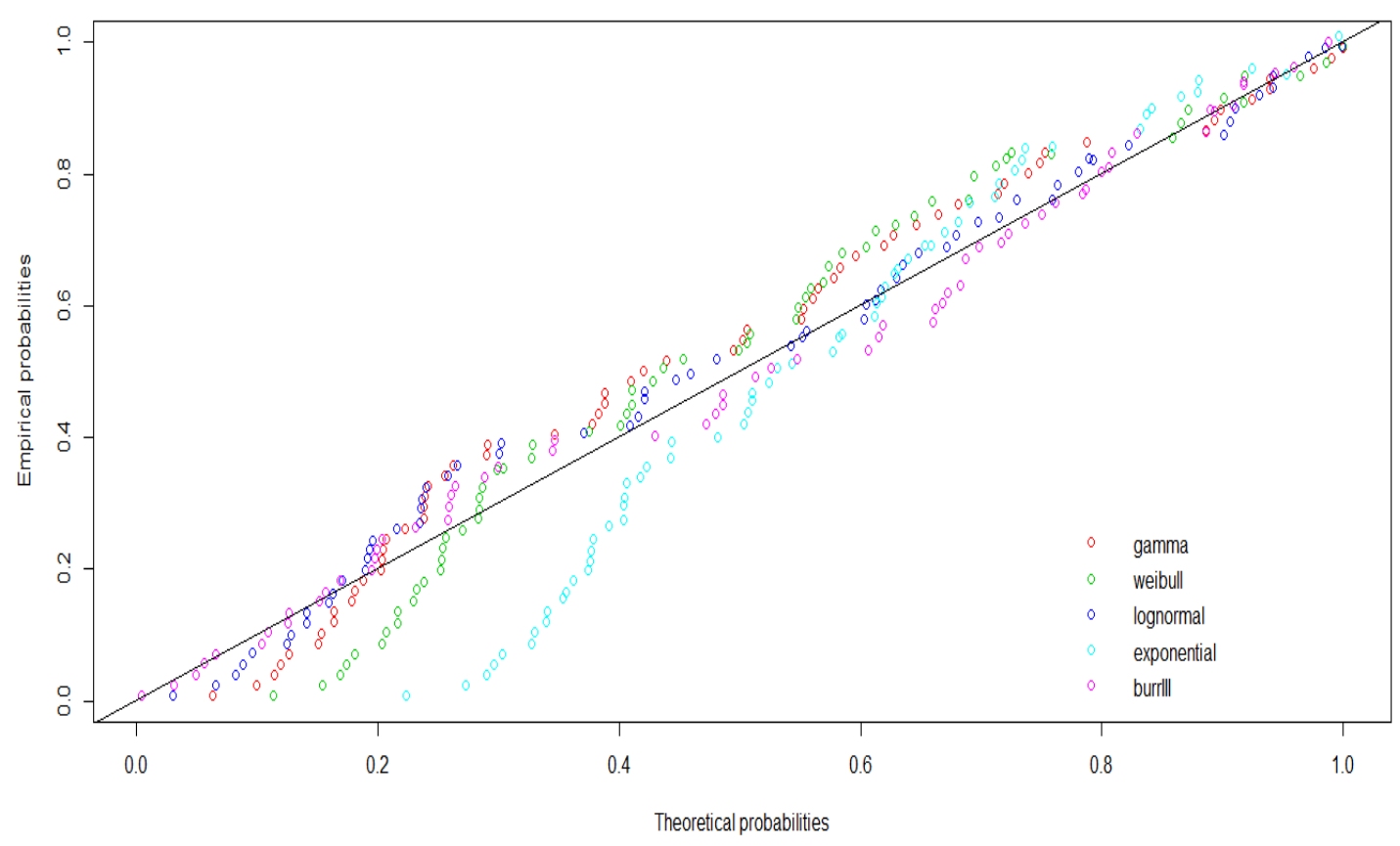

Şekil 6 Dağılımlara İlişkin P-P Grafikleri

Şekil 3- Şekil 6’ da ki grafikler Raphson yöntemi ve EM algoritmalarının incelendiğinde görüldüğü gibi Burr tipi III farklı sansürleme şemaları altında parametre dağılım veriye en uygun dağılımdır. Gerçek tahminlerinin karşılaştırmalarını yapabilmek yaşam verisinde, Burr tipi III dağılımı veriye için Tablo 11' de verilen sansürleme planları uygunluğu karar verildikten sonra Newton kullanılmıştır.

Tablo 11 Sansürleme Şeması

\begin{tabular}{cccc}
\hline Sansürleme Planları & $\mathbf{n}$ & $\mathbf{m}$ & $\mathbf{R}$ \\
\hline 1 & 63 & 20 & $\left(43,0^{* 19}\right)$ \\
2 & 63 & 30 & $\left(33,0^{* 29}\right)$ \\
3 & 63 & 40 & $\left(23,0^{* 39}\right)$ \\
4 & 63 & 50 & $\left(13,0^{* 49}\right)$ \\
\hline
\end{tabular}

Burada verilen sansürleme planında,

n: örneklem sayısı, m: başarısızlık sayısı, $\mathbf{R}$ : sansürleme şemasını, göstermektedir.

- Sansürleme planı 1' de görülen, $\mathrm{n}=63$ ve $\mathrm{m}=20$ olduğunda, 1.başarısızlık gerçekleştiğinde rasgele olarak veriden 43 gözlem çıkarılıyor. 2. ve 3. başarısızlıklar gerçekleştiğinde örneklemden gözlemler çekilmiyor.

- Sansürleme planı 2' de görülen, $\mathrm{n}=63$ ve $m=30$ olduğunda, 1.başarısızlık gerçekleştiğinde rasgele olarak veriden 33 gözlem çıkarılıyor. 2. ve 3. başarısızlıklar gerçekleştiğinde 
örneklemden gözlemler çekilmiyor.

- Sansürleme planı 3' de görülen, $n=63$ ve $\mathrm{m}=40$ olduğunda, 1.başarısızlık gerçekleştiğinde rasgele olarak veriden 23 gözlem çıkarılıyor. 2. ve 3. başarısızlıklar gerçekleştiğinde örneklemden gözlemler çekilmiyor.

- Sansürleme planı 4' de görülen, $\mathrm{n}=63$ ve $m=50$ olduğunda, 1.başarısızlık gerçekleştiğinde rasgele olarak veriden 13 gözlem çıkarılıyor. 2. ve 3 . başarısızlıklar

gerçekleştiğinde örneklemden gözlemler çekilmiyor.

Tablo 11'de verilen farklı sansürleme planları altında, gerçek veriye uygulamasını yapmış olduğumuz Burr tipi III dağılımı ilerleyen tür tip II sağdan sansürlü örneklemlerin $\alpha=2, \beta=1$ olduğu varsayılan durumda, Newton Raphson ve EM algoritmasına ilişkin tablo sonuçları Tablo 12' de verilmiştir.

Tablo 12 . $\alpha=2$ ve $\beta=1$ için, Newton Raphson-EM Algoritması Sonuçları

\begin{tabular}{ccccccc}
\hline & & & \multicolumn{2}{c}{$\mathrm{NR}$} & \multicolumn{2}{c}{ EM } \\
\hline $\mathrm{n}$ & $\mathrm{m}$ & $\mathrm{R}$ & $\hat{\alpha}$ & $\hat{\beta}$ & $\hat{\alpha}$ & $\hat{\beta}$ \\
\hline 63 & 20 & $\left(43,0^{* 19}\right)$ & 1.4866 & 2.3440 & 2.5241 & 0.9358 \\
63 & 30 & $\left(33,0^{* 29}\right)$ & 5.2797 & 1.0416 & 2.7469 & 1.0443 \\
63 & 40 & $\left(23,0^{* 39}\right)$ & 3.7198 & 0.7858 & 2.9107 & 1.1707 \\
63 & 50 & $\left(13,0^{* 49}\right)$ & 4.7460 & 0.7007 & 3.1776 & 1.3322
\end{tabular}

Tablo 12' de görüldü gibi, $\alpha=2$ ve $\beta=1$ olduğu durumda, farklı sansürleme planları altında elde edilen Newton Raphson yöntemi ve EM algoritması tahminlerine bakıldığında en iyi sansürleme planının 1 ve 2 . sansürleme planının olduğu görülmektedir. Burada, EM algoritmasının Newton Raphson yöntemine göre, parametre değerlerinin daha yakın sonuçlar verdiği 1. ve 2. sansürleme planı altında gerçekleştiğini söyleyebiliriz.

\section{Sonuç}

Bu çalışmada, Burr tipi III dağılımına ilişkin ilerleyen tür tip II sağdan sansürlü örnekleme dayalı parametrelerinin EM algoritmasıyla tahmini gerçekleştirilmiştir. Önerilen parametre tahmin edicilerinin performanslarını karşılaştırmak amacıyla $\mathrm{R}$ 3.1.3 programı kullanılarak Monte Carlo benzetim uygulanmıştır. İlerleyen tür tip II sağdan sansürlü örneklemin Burr tipi III dağılımı için, farklı parametre büyüklüklerinde, farklı örneklem genişliklerinde ve çeşitli sansürleme şemaları altında en çok olabilirlik tahmincileri Newton Raphson ve EM algoritması ile elde edilmiş olup bu parametre tahminleri her bir adımın $1000 \mathrm{kez}$ tekrarından elde edilen değerlerle bulunmuştur. EM algoritmasının performans1, Newton Raphson yöntemiyle karşılaştırılmıştır ve araştırmacılara performansı daha iyi sonuç veren EM 
algoritması önerilmiştir. Gerçek yaşam aralıkları karşılaştırıldığında ise, EM verisi, Badar ve Priest tarafindan 1982 aralıklarının Newton Raphson'a göre daha yılında basit bir fiber lifinden, 1000 dar olduğu gözlemlenmiştir. Her iki güven karbonluk fiber lifi içeren örneklere kadar aralığı da bilinmeyen parametre değerlerini elde edilmiştir. 1, 10, 20, 50 mm'lik fiber lifi çap uzunluklarını incelemişlerdir. Veriyi bu uzunlukları göz önüne alarak elde etmişler ve veriyi 20, 50, 150 ve $300 \mathrm{~mm}$ uzunluklarında GPA dayanıklılık testine tabi tutmuşlardır. Veri setinin $\mathrm{R} \quad 3.1 .3$ programında gerçekleştirilen uyum iyiliği testlerinden ve uyum iyiliği kriterlerinden en küçük sonucu vererek en iyi Burr tipi III dağılımına uyduğu gözlenmiştir. Farklı sansürleme planları altında elde edilen Newton Raphson ve EM algoritması tahminlerine bakıldığında EM algoritması parametre değerlerinin daha yakın sonuç verdiği görülmüşs ve araştırmacılara EM algoritması önerilmiştir. \%95 güven düzeyinde, EM algoritması ile elde edilen asimptotik güven aralıkları karşılaştırıldığında ise EM aralıklarının Newton-Raphson' a göre daha dar olduğu gözlemlenmiştir. Her iki güven aralığg da bilinmeyen parametre değerlerini içermiş olsa da EM algoritmasının Newton-Raphson yöntemine göre tercih edilebileceği ortaya konmuştur.

Sonuç olarak, gerçek yaşam verisi ve benzetim çalışmasında, EM algoritması ile elde edilen parametre tahminlerine ait MSE değerleri, Newton Raphson yöntemine göre daha küçüktür. \%95 güven düzeyinde, EM algoritması ile elde edilen asimptotik güven içermiş olsa da EM algoritması Newton Raphson yöntemine göre tercih edilir.

\section{Kaynaklar}

Aray S., (2018). "Burr Tipi III Dağılımının İlerleyen Tür Tip II Sağdan Sansürlü Örnekleme Dayalı Parametrelerinin EM Tahmin Edicisi”.Yüksek Lisans. Muğla Sitkı Koçman Ünv., Fen Bilimleri Enstitüsü. Muğla, 1-84.

Arabi Belaghi, R., Valizadeh Gamchi, F., Bevrani, H., Gürünlü Alma, Ö. 2016. "Estimation on Burr type III by progressive censoring using the EM and SEM algorithms". 13th Iranian Statistics Conference Shadid Bahonar University of Kerman 23-25 August 2016.

Bader, M.G. and Priest, A.M. (1982) "Statistical Aspects of Fibre and Bundle Strength in Hybrid Composites". In: Hayashi, T., Kawata, K. and Umekawa, S., Eds., Progress in Science and Engineering of Composites, ICCM-IV, Tokyo, 1129-1136.

Bairamov I, Eryılmaz S .,2006. "Spacings, exceedances and concomitants in progressive type II censoring scheme". Journal of Statistical Planning and Inference 136(3), 527-536.

Balakrishnan and Sandhu 1995. "A simple simulation algorithm for generating progressive Type-II censored sample". American Statisticians. 49:229-230.

Balakrishnan, N. and Aggarwala, R. 2000. "Progressive Censoring: Theory, Methods and Applications". Birkhäuser, Boston. 
Burr, I. W., 1942. "Cumulative frequency McKendrick, A.G., 1926. "Applications of functions". The Annals of mathematical mathematics to medical problems". Proc. statistics 13(2): 215-232.

Edinb. Math. Soc.13, 98-130.

Demir, E. 2015. "Eğitim bilimlerinde olay Nelson, W. 1982, "Applied Life Data geçmişi çözümlemesi”, Uluslarası Sosyal Analysis”. Wiley, New York, 584.

Araştırmalar Dergisi, Cilt 8:570-582

Ng T., Chan CS., Balakrishnan N.,2002.

Dempster, A.P., Laird, N.M, and Rubin, D., "Estimation of parameters from progressively 1977. "Maximum likelihood estimation from censored data using EM algorithm". incomplete data via the EM algorithm", Computational Statistics and Data Analysis, Journal Royal Statistical Soc. Vol: 39, 1-38. 39, 371-386.

Fesler, J.A. and Hero, A.O., 1994." Space- Rastogi M., Tripathi Y., 2013. "Inference on alternating generalized expectation unknown parameters of a Burr distribution maximization algorithm". IEEE Transactions under hybrid censoring". Statistical Papers, on Signal Processing, 42, 2664-2677.

Springer, 54(3), 619-643.

Gupta, R. D., \& Kundu, D., 2001) Saraçoğlu, B., Kınac1, İ., Kuş, C. 2006. "Exponentiated Exponential Family:an "Power Hazard Fonksiyonuna Sahip Dağılım Alternative to Gamma and Weibull Fonksiyonlarının Parametrelerinin İlerleyen Distribution". Biometrika 43, 117-130. Tür Tip II Sağdan Sansürlü Örneklemlere İnceoğlu, F. (2013), “Sağkalım analizi yöntemleri ve karaciğer nakli verileri ile bir uygulama”. Yüksek Lisans, Inönü Üniversitesi, Tadikamalla, P. R. (1980). “A look at the Burr Malatya, 142s.

Kale, B. 2003. "İlerleyen Tür Sansürlenmiş Sira İstatistikleri:Dağılım Özellikleri Ve Uygulamalar". Yüksek Lisans Tezi, Ankara Terzi, Y. 2003. "Sansürlü Veriler İçin Üniversitesi Fen Bilimleri Enstitüsü. Dayalı En Küçük Kareler Tahmini”. 5. İstatistik Günleri Sempozyumu(82). and related distributions". International Statistical Review/Revue Internationale de Statistique: 337-344.

Kus C., 2004. "Bazı yaşam zamanı Uygulaması", Doktora Tezi, Ondokuz Mayıs dağılımlarının parametrelerinin tam ve Üniversitesi Fen Bilimleri Enstitüsü.

sansürlü verilere dayalı tahmini", S.Ü. Fen Yazıcı, F. 2005. "EM Algoritmas1 ve Bilimleri Enstitüsü, Doktora tezi.

Uzant1ları", Ankara, 85s.

Kuş, C. 2005. “İlerleyen Tür Tip II Sağdan Sansürlü Örnekleme Dayalı Düzgün Dağılımın Parametrelerinin Jackknife Tahmin Edicisi”. Ístanbul Üniversitesi Iktisat Fakültesi Zhu HT, Lee SY, Wei BC, Zhou J. 2001. "Case-Deletion Measures for Models With Incomplete Data".Biometrika. 88:727-737. Ekonometri ve İstatistik Dergisi, 2, 11-29.

Louis, T.1982. A., "Finding the observed information matrix when using the EM algorithm". J. Roy. Statist. Soc. Ser. B, 44, 226-233. 